American J. of Engineering and Applied Sciences 3 (3): 545-551, 2010

ISSN 1941-7020

(C) 2010 Science Publications

\title{
Assessment of Thermal Comfort in Respect to Building Height in a High-Density City in the Tropics
}

\author{
Anisha Noori Kakon, Mishima Nobuo, Shoichi Kojima and Taguchi Yoko \\ Department of Architecture and Civil Engineering, Saga University, Saga, Japan
}

\begin{abstract}
Problem statement: The significance of urban design and planning in the tropics lies mostly on its climatic and regional concerns. Among many design parameters, building height is an important parameter which affects thermal climate in the city considerably. This study investigated the effect of building height on outdoor thermal comfort during the daytime in summer in Dhaka, Bangladesh which is a high density city located in tropical climate zone. This study emphasized on pedestrian comfort condition in a planned residential area in the city. Approach: Thermal comfort was assessed in terms of Temperature-Humidity-Index (THI) which uses air Temperature $\left(\mathrm{T}_{\mathrm{a}}\right)$ and Relative Humidity (RH). Measurements were carried out in a typical summer day. In addition, to simulate the urban thermal climate, a 3D numerical simulation tool ENVI-met was used. Results: Simulated results showed close agreement with the measured data in case of existing canyon and thus the validity of the present numerical simulation was confirmed. Results showed that in case of existing canyon with average building height of 4-5 storied, THI lies in the discomfort level. A canyon was proposed by increasing the building height to 8-10 storied in the existing canyon. In case of proposed canyon, it was found that increased building height provides comparatively comfortable condition than the existing case during day time. Moreover, mean radiant temperature $\left(\mathrm{T}_{\mathrm{mrt}}\right)$, surface Temperature $\left(\mathrm{T}_{\mathrm{s}}\right)$ and wind speed were included in the present study to identify the effects of building height on these factors. Conclusion: The present study had an implication on the urban design process to achieve a more comfortable urban environment by mitigating heat stress in summer.
\end{abstract}

Key words: Tropical city, building height, thermal comfort, temperature humidity index

\section{INTRODUCTION}

Rapid urbanization in the tropics has brought in its wake many hitherto changes to the physical environment of the cities. Climate change is one of those that have large effects on the health and wellbeing of humans, animals and plants in a city. Thus the integration of climate dimension in the city planning and design process has become a vital issue now-adays. Yet, urban design and planning policy instruments for the mitigation of the negative impacts of tropical urban climate remains largely unexplored in this region (Emmanuel, 2005). Among the urban design elements, urban density is an important one. A given urban density can result from independent design features, which affect urban climate in different ways such as: Fraction of urban land covered by buildings, distances between buildings, including streets' width, average height of buildings (Watson, 2003).

Therefore, the height of building is an independent design feature can affect urban density as well as the urban climate in many ways. Studies in Pune, India showed that the unplanned rising of building height causes the discomfort in the city (Deosathali, 1999). In case of Colombo, Sri Lanka, it was found that the wide streets with low-rise buildings and no shade trees makes the outdoor conditions worst and the most comfortable conditions were found in the narrow streets with tall buildings, especially if shade trees were present (Johansson and Emmanuel, 2006).

This research is based on Dhaka, Bangladesh, a location in the tropical monsoon climate zone. Presently, in Dhaka city, increasing the heights of buildings is commonly adopted to cope with the rapid urbanization. Moreover, heat stress in summer is a growing environmental concern for the city. Thus, there is an urgent need to assess the effects of building height on outdoor thermal climate in the city. In this study, the thermal climate is assessed by taking into account air and surface temperature, mean radiant temperature, humidity and wind speed. This study is mainly concerned with the climatic aspects within the urban canopy layer focusing on pedestrian comfort.

Corresponding Author: Anisha Noori Kakon, Department of Architecture and Civil Engineering, Saga University, Saga, Japan 
Study area: Dhaka city is a fast growing mega city in the world located at $23.24^{\circ} \mathrm{N}, 90.23^{\circ} \mathrm{E}$ and $8.8 \mathrm{~m}$ a.s.l. About 13 million people live in the metropolitan area and the density of population is about 23,029 persons per sq. $\mathrm{km}$ in the capital city. To accommodate this large population, the city is growing both horizontally and vertically. This study is based on Dhanmondi residential area located at the southern part of the city. Up to 2006 the height limitation of building was 6storied in this area. The average height of the building, $\mathrm{H}$ in this area is about 4-storied and height of 1-storied building is $3 \mathrm{~m}$. The canyon (Width, $\mathrm{W}=26 \mathrm{~m}$ ) selected for this study is shown by the dashed rectangle in Fig. 1. The pedestrian ways of approximately $3 \mathrm{~m}$ wide are found on both the sides of road. The orientation of canyon is $30^{\circ} \mathrm{NW}-\mathrm{SE}$. This study is carried out for hot and dry summer conditions in April. During this season, the probabilistic extreme predicted the maximum temperatures in April to be as high as $39.1^{\circ} \mathrm{C}(1$ in 4 years), $40.2^{\circ} \mathrm{C}$ ( 1 in 10 years) and $41.0^{\circ} \mathrm{C}$ ( 1 in 25 years) (Karmakar and Khatun, 1993).

Increasing building height: Model canyon: At present, the growth and development of Dhaka city is regulated by the Dhaka Metropolitan Development Plan (DMDP) 1995-2015. One of the major features of the preferred strategies of this plan is: Allowing concentrated development via relaxed building height and plot coverage rules and regulations (RAJUK, 1997). As a result, the previous rule regarding height limitation has been relaxed allowing higher buildings in some parts of the city. In this study, the existing buildings lower than 10 stories are extended by a maximum of 4 stories to attain heights of 10 stories. The heights of 5 very small-sized buildings are remained unchanged. This limited increase of building height is considered here because the building coverage, set back and other guidelines are different for buildings higher than 10 stories. Moreover, if all buildings are of the same height, wind speed and natural ventilation at street level are decreased (Johansson and Emmanuel, 2006). The ground coverage, design and materials of the buildings are considered to be unchanged. The layouts of existing canyon with building heights (in meter) and proposed heights in model canyon (in parentheses) are shown in Fig. 2.

After increasing building height, the average aspect ratio $\mathrm{H} / \mathrm{W}$ of this canyon is increased from $0.47-0.86$. Figure 3 shows the Sky View Factors (SVF) at a height of $1.2 \mathrm{~m}$ above the ground for the existing and model canyons.

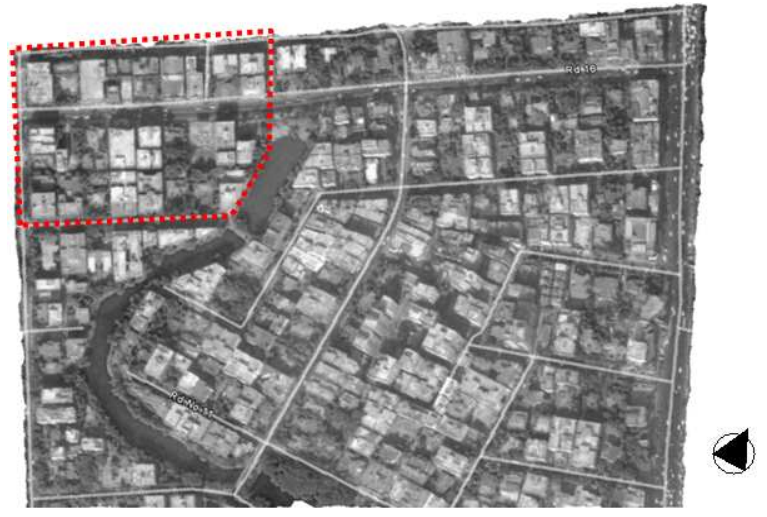

Fig. 1: Study area in Dhanmondi, Dhaka

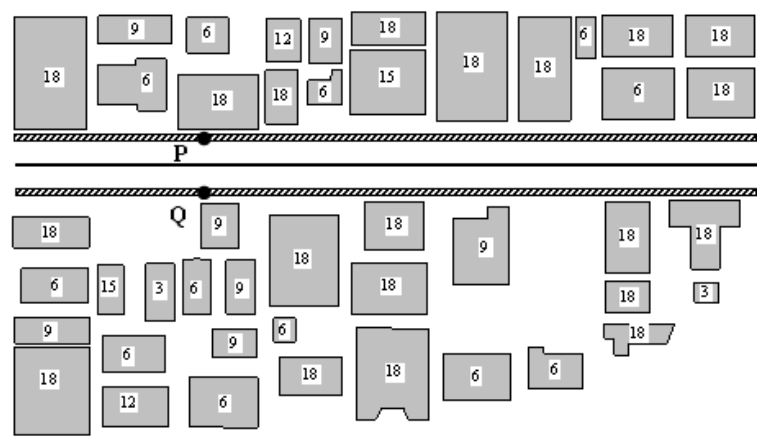

(a)

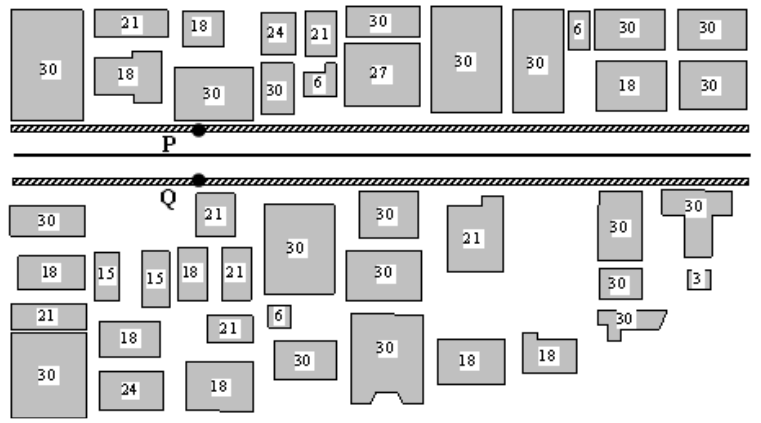

(b)

Fig. 2: layout of (a) existing and (b) model canyon

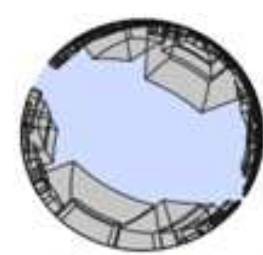

(a) $\mathrm{SVF}=51.1$

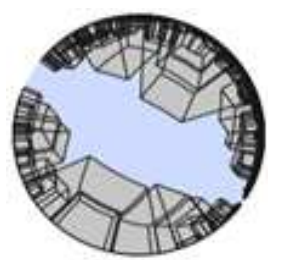

(b) $\mathrm{SVF}=35.0$
Fig. 3: Sky view factors of (a) canyon and (b) model canyon 


\section{MATERIALS AND METHODS}

Field survey and measurement: A detailed field survey of the study area was conducted in April 2009 to investigate some building data: layout, height, materials and so on. Again air temperature $\mathrm{T}_{\mathrm{a}}$ and relative humidity RH were measured by using Thermo Recorder TR-72U in the study area in April 10-20. The data was recorded from 7:30 am-18:30 pm.

Numerical modeling: The present microclimate is evaluated by using a three-dimensional numerical model ENVI-met (Bruse, 2009) which simulates the microclimatic changes within urban environments in a high spatial and temporal resolution. This model calculates all important meteorological parameters such as air and surface temperature, wind speed, humidity, radiation as well as mean radiant temperature. The versatility and validity of the ENVI-met were confirmed from the previous studies (Wong et al., 2007; Emmanuel et al., 2007). For temporal stability of the numerical simulation, the time step is kept below 10s. The basic input parameters for simulation are given in Table 1.

Thermal comfort assessment: Several attempts had been made to synthesize the range of factors defining the boundaries of thermal comfort in a single index. The efforts to quantify thermal comfort in the tropics began more than sixty years ago. These include Ellis who recorded "comfort" (or neutral) temperature to be 26.1-26. $7^{\circ} \mathrm{C}$ in Singapore, Webb recorded a comfort temperature of $27.2^{\circ} \mathrm{C}$ also in Singapore, Rao defined comfort temperature of $26.0^{\circ} \mathrm{C}$ in Calcutta and Nicol recorded $31.1^{\circ} \mathrm{C}$ in Roorkee, India (Emmanuel, 2005). Indeed, outdoor thermal comfort condition ought to be expressed in a combination of the factors such as air temperature, relative humidity, air velocity and radiation, instead of a single value. The indicator which is selected to assess the thermal comfort for this study is Temperature Humidity Index (THI).

\begin{tabular}{ll} 
Table 1: Basic input parameters for simulation \\
\hline Location & Dhaka, Bangladesh, $23.24^{\circ} \mathrm{N}$, \\
& $90.23^{\circ} \mathrm{E}, 8.8 \mathrm{~m}$ a.s.l. \\
$\begin{array}{l}\text { Simulation day } \\
\text { Tymulation duration }\end{array}$ & From $7: 30-18: 30(11 \mathrm{~h}$ ) \\
$\begin{array}{l}\text { Spatial resolution } \\
\text { Wind speed and direction }\end{array}$ & $210 \times 80 \times 25$ grids, grid size: $2 \times 2 \times 3 \mathrm{~m} \mathrm{sec}$ \\
Initial temperature of & $293 \mathrm{~K}$ \\
atmosphere & \\
Relative humidity & $40 \%$ \\
Heat transmission $180^{\circ}$ (south) & Walls: $1.7 \mathrm{~W} \mathrm{~m}^{-2} \mathrm{~K}$ \\
& Roofs: $2.2 \mathrm{~W} \mathrm{~m}^{-2} \mathrm{~K}$ \\
Albedo & Walls: 0.3 \\
& Roofs: 0.15 \\
\end{tabular}

Temperature Humidity Index (THI): Temperature Humidity Index (THI) also known as Discomfort Index (DI) is one of the variants of Effective Temperature (ET), developed by Thom (1959). It combines the wet and dry bulb temperatures into a scale that imitates the thermal sensation of a human being. Later Nieuwolt (1998) modified the index using air temperature and relative humidity. Especially in a case where relative humidity data is more frequently available than the wet bulb temperature, then the following equation can be used:

$$
\mathrm{THI}=0.8 \mathrm{~T}_{\mathrm{a}}+\frac{\mathrm{RH} \times \mathrm{T}_{\mathrm{a}}}{500}
$$

Where:

$\mathrm{T}_{\mathrm{a}}=$ The air temperature $\left({ }^{\circ} \mathrm{C}\right)$

$\mathrm{RH}=$ The relative humidity $(\%)$

By empirically testing the THI values on human objects, the comfort limits are defined as:

$21 \leq \mathrm{THI} \leq 24=100 \%$ of the subjects felt comfortable $24<\mathrm{THI} \leq 26=50 \%$ of the subjects felt comfortable $\begin{aligned} & \text { THI }>26=100 \% \text { of the subjects felt uncomfortably } \\ & \text { hot }\end{aligned}$

However, it must be mentioned that the above ranges were developed in the mid-latitudes Tropical residents are likely to tolerate higher levels of THI due to acclimatization as well as variations in food habitats and clothing (Emmanuel, 2005).

\section{RESULTS AND DISCUSSION}

Figure 4 shows the measured and simulated air temperatures $T_{a}$ in a day of April for the existing canyon. Though some differences exist between measurements and simulation, it is found that ENVImet can predict diurnal temperatures more accurately. Furthermore, a strong correlation $\left(\mathrm{R}^{2}=0.91\right)$ exists between them. Thus the validity of ENVI-met simulation is confirmed for the present research.

Results of measured data: By using measured data of air temperature and relative humidity, THI is calculated which are presented in Fig. 5. The ranges of THI is 29.2-33.4 and $27-35.2^{\circ} \mathrm{C}$ for points $\mathrm{P}$ and $\mathrm{Q}$, respectively which indicates values of thermal discomfort. The distribution pattern of THI is different during different hours of the day on the two points on two sides of the canyon. At point $\mathrm{P}$, THI is higher during morning till noon and the maximum is $33.4^{\circ} \mathrm{C}$ at 12:30 LST. While at point Q, THI rises in the afternoon hours and the highest is at $15: 30 \mathrm{LST}$ which is $35.2^{\circ} \mathrm{C}$. 


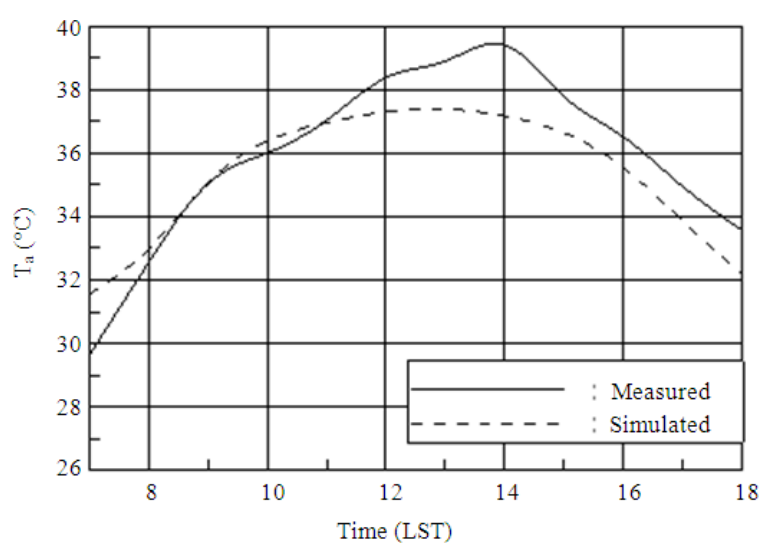

Fig. 4: Comparison between measured and simulated air temperature $\mathrm{T}_{\mathrm{a}}$

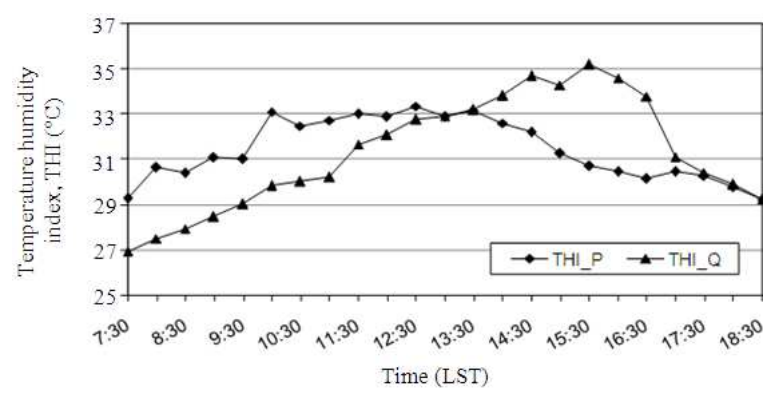

Fig. 5: Diurnal distribution of temperature humidity index THI at points $\mathrm{P}$ and $\mathrm{Q}$

Simulation results of existing and model canyon: The existing and the model canyons of the study area are compared with respect to air temperature $\mathrm{T}_{\mathrm{a}}$ and relative humidity RH. Then the THI is calculated using simulated data of $T_{a}$ and RH. Furthermore mean radiant temperature $T_{m r t}$, surface temperature $T_{s}$ and the wind speed are also simulated inside the existing and model canyons. Some significant thermal climatic parameters are discussed in the followings at points $\mathrm{P}$ and $\mathrm{Q}$ on the pedestrian ways (shown in Fig. 2). Parameters are assessed at a height of $1.2 \mathrm{~m}$ above the ground.

Air Temperature $\left(T_{a}\right)$ and Relative Humidity $(\mathrm{RH})$ : Figure 6 shows the distributions of air Temperature $\left(T_{a}\right)$ and Relative Humidity (RH) in the existing and model canyons during daytime at points $\mathrm{P}$ and $\mathrm{Q}$. It shows that $\mathrm{T}_{\mathrm{a}}$ decreases and RH increases in the model canyon all through the day at both the points. In fact the higher the Sky View Factor (SVF) the larger the solar radiation in urban canyon (Kakon and Nobuo, 2009). The SVF of the model canyon is lower Fig. 3 due to the increased building height. As a result the incoming solar radiation

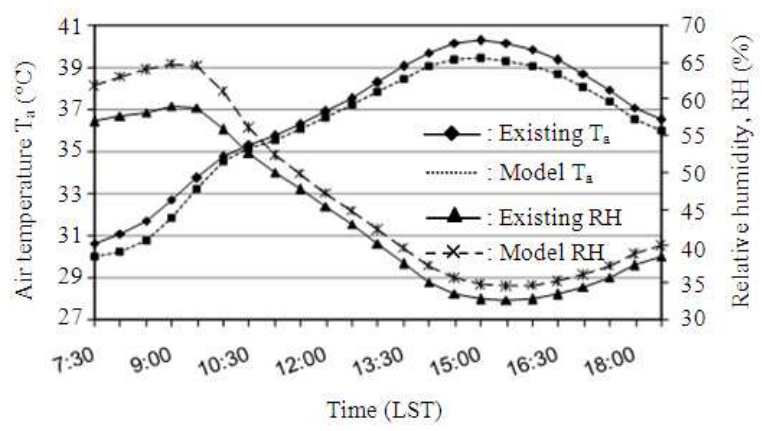

(a)

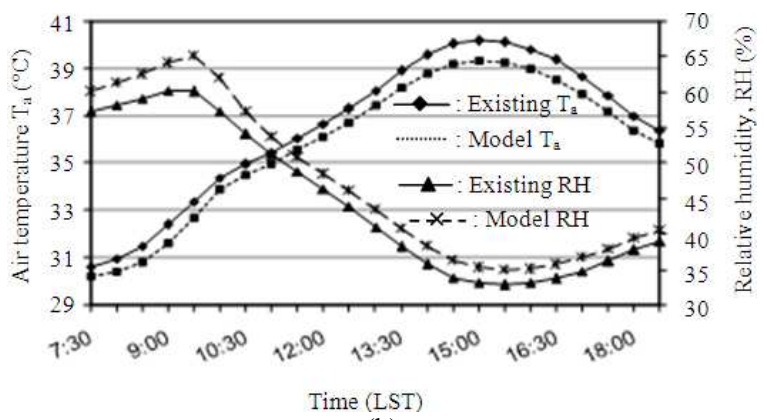

(b)

Fig. 6: Diurnal distribution of air temperature $T_{a}$ and relative humidity $\mathrm{RH}$ in the existing and model canyons at point (a) P and (b) Q

is lower in the model canyon than the existing one resulting decreases in $T_{a}$. At point $P$, the range of $T_{a}$ is $30.7-40.3^{\circ} \mathrm{C}$ in the existing canyon while in the model canyon $\mathrm{T}_{\mathrm{a}}$ rang is $30.0-39.5^{\circ} \mathrm{C}$ (Fig. 6a). On the other hand at point Q (Fig. 6b), the range of $\mathrm{T}_{\mathrm{a}}$ is $30.6-40.2^{\circ} \mathrm{C}$ in the existing canyon while in the model canyon the range is $30.2-39.3^{\circ} \mathrm{C}$. The average differences of $\mathrm{T}_{\mathrm{a}}$ between the existing and model canyons at point $\mathrm{P}$ and $\mathrm{Q}$ are 0.56 and $0.66^{\circ} \mathrm{C}$, respectively. The highest temperature was found at 15:00LST for all the cases. At point $\mathrm{P}$ the average $\mathrm{RH}$ in the existing canyon is $44 \%$ while it is $46.8 \%$ in the model canyon. Again, at point $\mathrm{Q}$ the average $\mathrm{RH}$ is increased from $44.5 \%$ in existing canyon to $47.1 \%$ in the model canyon.

Temperature Humidity Index (THI): The relative assessment of thermal comfort in the existing and model canyons are presented in Fig. $7 \mathrm{a}$ and $7 \mathrm{~b}$ for points $\mathrm{P}$ and $\mathrm{Q}$, respectively. It shows that THI is found greater than 30 from 9:30-18:30 LST both in the existing and model canyons. THI decreases considerably in the model canyon during daytime. This indicates an improvement of comfort condition to some extent. At point $\mathrm{P}$ THI decreases by $0.57^{\circ} \mathrm{C}$ (which is highest) at 15:30 LST in the model canyon. 


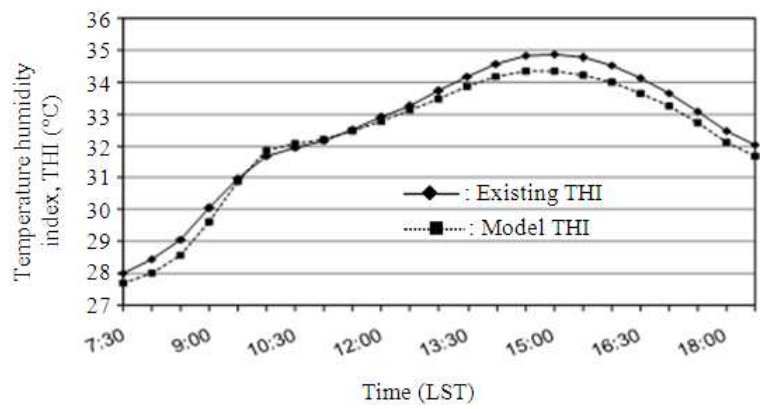

(a)

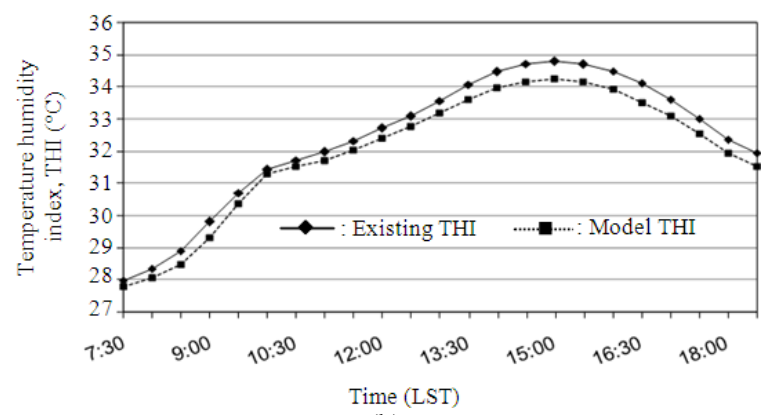

(b)

Fig. 7: Comparison of temperature humidity index, THI between the existing and model canyons at point (a) P and (b) Q

While at point $\mathrm{Q}$, the maximum decrease in THI is by $0.59^{\circ} \mathrm{C}$ in the model canyon at $16: 30 \mathrm{LST}$.

Mean radiant Temperature $\left(\mathbf{T}_{\mathrm{mrt}}\right)$ : Figure 8 shows the diurnal distribution of mean radiant temperature $T_{\text {mrt }}$ in the existing and model canyons. Unlike air temperature, $T_{\text {mrt }}$ shows a totally different pattern in different hours of the day. Indeed, $\mathrm{T}_{\mathrm{mrt}}$ is always related to the radiation fluxes received by a standing human. Figure 8 shows that, $\mathrm{T}_{\mathrm{mrt}}$ decreases variably in the model canyon during different hours of the day. In case of point $\mathrm{P}$ the significant difference is found in some hours in the morning during 7:30-8:00 LST and in the afternoon during 15:00-16:00 LST. At 15:30 LST the difference of $\mathrm{T}_{\mathrm{mrt}}$ is the highest which is $43^{\circ} \mathrm{C}$. On the other hand at point Q (Fig. 8b) in the morning hours although $\mathrm{T}_{\mathrm{mrt}}$ is slightly higher in the model canyon, it decreases largely during 11:00-12:00 LST. Again in the afternoon at 16:30 LST the decrease in $\mathrm{T}_{\text {mrt }}$ is highest which is $38^{\circ} \mathrm{C}$.

Surface temperature $\left(\mathbf{T}_{\mathrm{s}}\right)$ : Figure 9 illustrates the distribution of surface temperature $T_{s}$ of the existing and model canyons in different hours of the day at points $P$ and $Q$. Similar to air temperature $\left(T_{a}\right)$, surface temperature also decreases in the model canyon than in the existing canyon during most of the hours of the day.

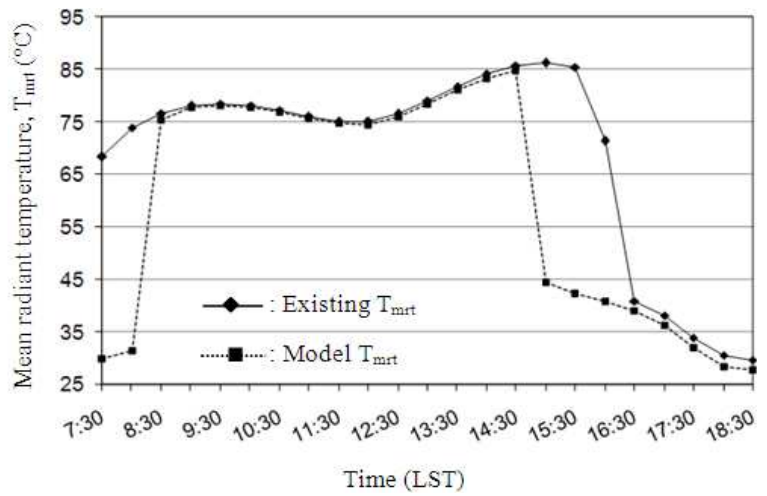

(a)

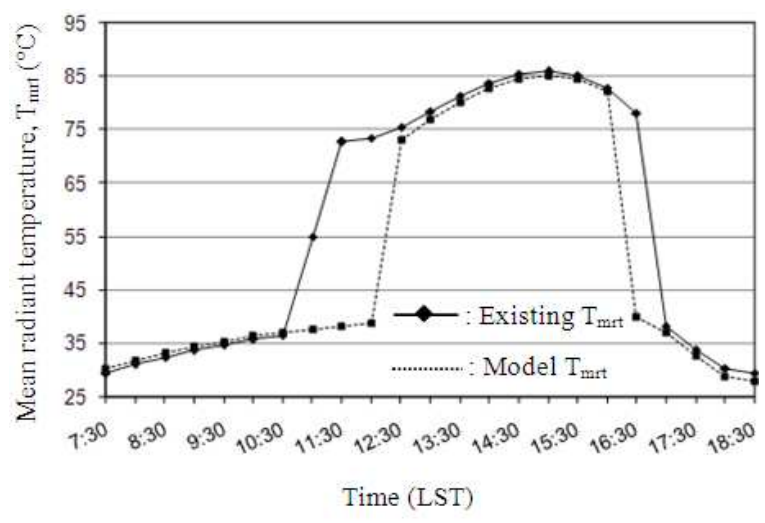

(b)

Fig. 8: Diurnal distribution of mean radiant temperature $\mathrm{T}_{\mathrm{mrt}}$ in existing and model canyons at points (a) $\mathrm{P}$ and (b) Q

It follows the similar pattern of $\mathrm{T}_{\mathrm{mrt}}$. At point $\mathrm{P}$ (Fig. 9a), $\mathrm{T}_{\mathrm{s}}$ decreases significantly in the afternoon during 15:00-16:30 LST and it decreases by maximum of $7.1^{\circ} \mathrm{C}$ at $15: 30 \mathrm{LST}$. While at point Q (Fig. 9b), $\mathrm{T}_{\mathrm{s}}$ decreases largely during 11:30-13:00 LST. At this point the maximum difference is found $10.9^{\circ} \mathrm{C}$ at $12: 00 \mathrm{LST}$. The significant fall of $T_{s}$ is mainly due to the effect of shading in the model canyons due to increased building height.

Wind speed (v): The wind speed, $\mathrm{v}$ increases to some extent in the model canyon all over the day. The vector maps of wind speed in the existing and model canyons at 12:00 LST are shown in Fig. 10. Since the wind direction is from the south, the direction of wind in the canyon depends on its orientation. In the model canyon at 12:00 LST, $v$ increases by 0.3 and $0.01 \mathrm{~m} \mathrm{sec}^{-1}$ at point $\mathrm{P}$ and $\mathrm{Q}$, respectively. 


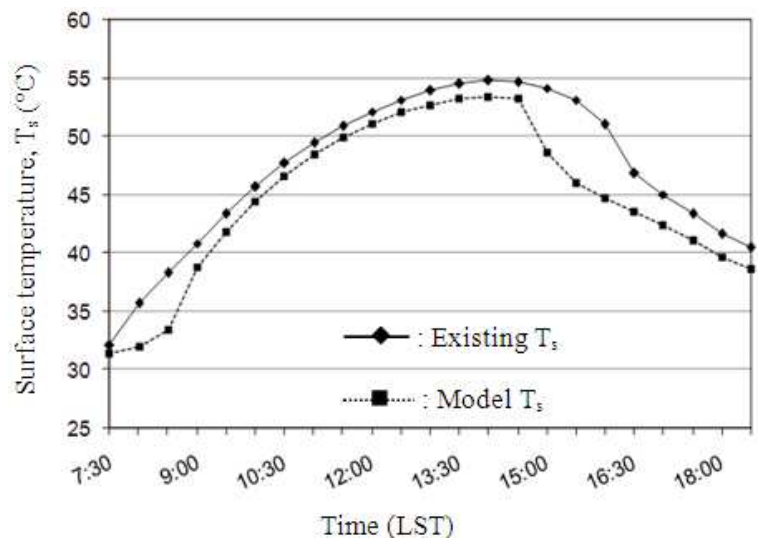

(a)

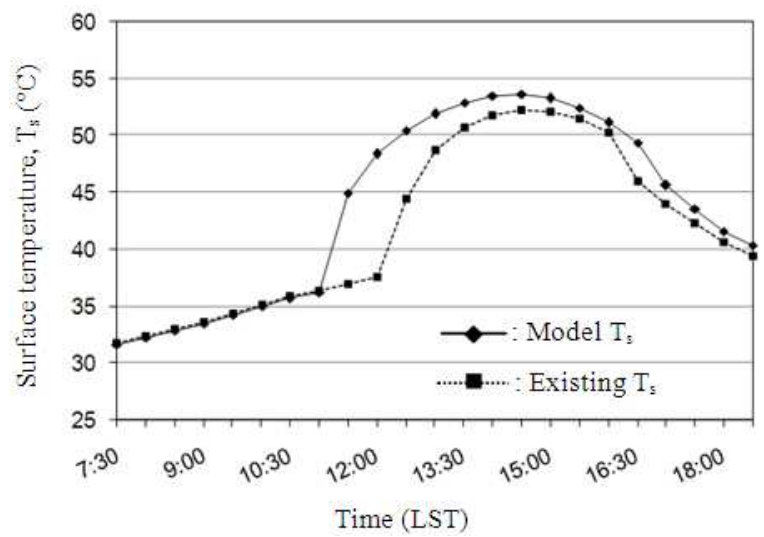

(b)

Fig. 9: Diurnal distribution of surface temperature $\mathrm{T}_{\mathrm{s}}$ in the existing and model canyons at points (a) $\mathrm{P}$ and (b) $\mathrm{Q}$

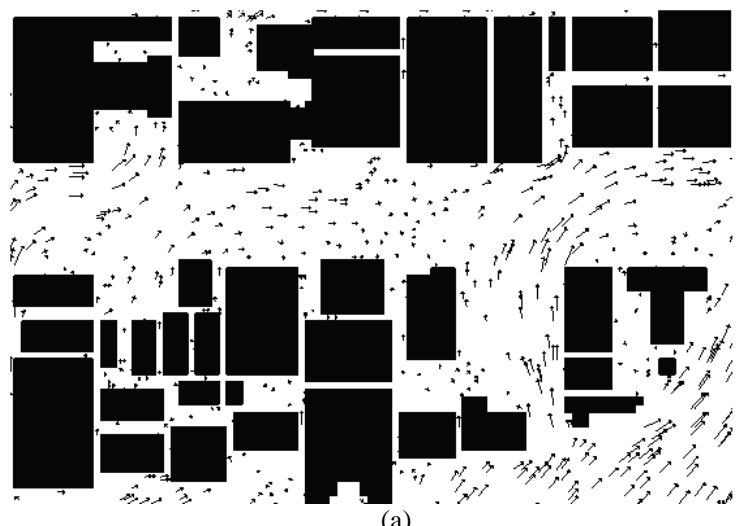

(a)

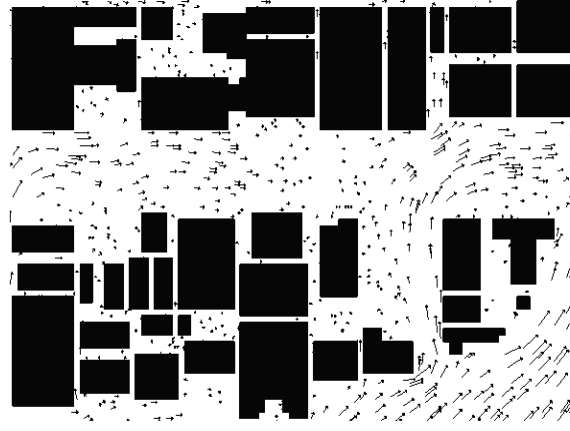

(b)

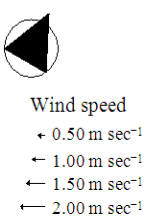

$-2.00 \mathrm{~m} \mathrm{sec}^{-1}$

Fig. 10: Vector maps of wind speed, v inside (a) existing and (b) model canyons at 12:00 LST

\section{CONCLUSION}

The present study has compared the condition of thermal climate in an existing urban canyon and in the same canyon with increased building height. It is found that the air temperature decreased to some extent in the canyon with increased building height. As a result temperature humidity index also reduces in the canyon with increased building height. Moreover it is revealed that during some hours of the day mean radiant temperature and surface temperature dropped largely in the canyon with increased building height than the existing canyon. It is also observed that the wind speed is increased in model canyon. The present study demonstrated that the policy to increase building height to some extent can offer a preferable thermal climate in case of a high density city where to cope with urbanization is a challenging issue. Further, the results obtained from this research can contribute to the urban design process to achieve a more comfortable urban environment by mitigating heat stress in summer.

\section{ACKNOWLEDGEMENT}

This study was partially supported by the Sasakawa Scientific Research Grant from Japan Science Society.

\section{REFERENCES}

Bruse, M., 2009. ENVI-Met. http://www.envi-met.com Deosathali, V., 1999. Assessment of impact of urbanization on climate: An application of bioclimatic index. Atmosp. Environ., 33: 4125-4133. DOI: 10.1016/S1352-2310(99)00154-5

Emmanuel, R., 2005. Thermal comfort implications of urbanization in a Warm-Humid City: The Colombo Metropolitan Region (CMR), Sri Lanka. Build. Environ., 40: 1591-1601. DOI: 10.1016/J.BUILDENV.2004.12.004 
Emmanuel, R., H. Rosenlund and E. Johanson, 2007. Urban shading-a design option for the tropics. A study in Colombo, Sri Lanka. Int. J. Climatol., 27: 1995-2004. DOI: 10.1002/joc. 1609

Johansson, E. and R. Emmanuel, 2006. The influence of urban design on outdoor thermal comfort in the Hot Humid City of Colombo, Sri Lanka. Int. J. Biometeorol., 51: 119-133. DOI: 10.1007/s00484006-0047-6

Kakon, A.N. and M. Nobuo, 2009. The sky view factor effect on the microclimate of a city environment: A case study of Dhaka City. Proceedings of the 7th International Conference on Urban Climate, June 29-July 3, Yokohama, Japan, pp: 1-4. http://www.ide.titech.ac.jp/ icuc7/extended_abstra cts/pdf/384760-1-090513144446-003.pdf

Karmakar, S. and A. Khatun, 1993. On the variability and probabilistic extremes of some climatic elements over Dhaka. Proceedings of the International Technical Conference on Tropical Urban Climates, Mar. 1993, World Meteorological Organization, Dhaka, Bangladesh, pp: 588.
Nieuwolt, S., 1998. Tropical Climatology. 2nd Edn., John Wiley and Sons Inc, New York, ISBN: 9780471966104, pp: 339.

RAJUK, 1997. Dhaka Metropolitan Development Plan 1995-2015 Vol. 1: Dhaka Structure Plan. 1st Edn., Government of the People's Republic of Bangladesh, Dhaka, pp: 102.

Thom, E.C., 1959. The Discomfort Index. Weatherwise, 12: 57-60.

Watson, D., 2003. Time-Saver Standards for Urban Design. 1st Edn., McGraw-Hill, New York, ISBN: 978-0070685079, pp: 960.

Wong, N.H., S.K. Jusuf, A.A.L. Win, H.K. Thu and T.S. Negara, 2007. Environmental study of the impact of greenery in an institutional campus in the tropics. Build. Environ., 42: 2949-2970. DOI: 10.1016/j.buildenv.2006.06.004 